\title{
STRUCTURED SETTLEMENTS
}

\author{
NINA L. FOSTER*
}

\begin{abstract}
The author explores the growth and development of the structured settlement in Canada as a means of assessing damages for injuries and fatalities. The procedure for entering into and implementing a structured settlement is presented with illustrative examples. The author analyzes both the advantages, such as savings in taxes and insurance, and the disadvantages of a structured settlement in arguing that it represents a valuable alternative among compensation techniques.
\end{abstract}

\section{INTRODUCTION}

Awards in Canada for serious bodily injury and fatal accidents have been steadily increasing in recent years. The Supreme Court of Canada in the Trilogy, ${ }^{1}$ and more recently in Lewis v. Todd ${ }^{2}$ and Lindal v. Lindal ${ }^{3}$ has tried to establish some guidelines and in doing so expressed some concern as to the adequacies of our conventional methods of assessing damages. In Andrews v. Grand \& Toy, Dickson J. said: ${ }^{4}$

The subject of damages for personal injury is an area of the law which cries out for legislative reform. The expenditure of time and money in the determination of fault and of damage is prodigal.

The disparity resulting from lack of provision for victims who cannot establish fault, must be disturbing. When it is determined that compensation is to be made, it is highly irrational to be tied to a lump sum system and a once-and-for-all award.

The Holland Committee on Tort Compensation was formed in response to those comments and its report was published in August of $1980 .{ }^{5}$ That report reviews various alternatives to our present lump sum award approach but concludes that neither periodic reviews of damage assessments nor final awards ordering defendants to make periodic payments would be feasible. It urges that a cautious approach to change be taken and recommends that the courts be allowed to order provisions either for review or periodic payments, but only with the consent of all parties involved. The British Law Commission ${ }^{6}$ had earlier come to similar conclusions.

It is the conclusion of the Holland Committee that implementation of a system of periodic review of personal injury assessments is not at all practical at this time and that no scheme of periodic payments should be forced upon the parties without their consent. The question then is what viable alternatives to the conventional lump sum damage award do exist or can be developed to try to alleviate the concerns being expressed about lengthy and overly complicated trials, the dangers of undercompensation and over-compensation or windfall, and, further, the concern of the public that ever increasing damage awards will ultimately mean higher insurance premiums for everyone. Awards in the United

- LL.B. (Alta.) With the firm of Foster Chatwin \& Belzil.

1. Andrews v. Grand \& Toy [1978]2 S.C.R. 229, 8 A.R. 182, 3 C.C.L.T. 225, [1978]1 W.W.R. 577, 19 N.R. 50. 83 D.L.R. (3d) 452; Thornton v. Bd. of School Trustees of School Dist. No. 57(Prnce George) [1978]2 S.C.R.267,3 C.C.L.T.257,[1978]1 W.W.R.607, 19. N.R.552, 83 D.L.R. (3d) 480; A rnold v. Teno [1978] 2 S.C.R. 287, 3 C.C.L.T. 272, 19 N.R. 1, 83 D.L.R. (3d) 609 .

2. [1980] 2 S.C.R. 694, 14 C.C.L.T. 294, 34 N.R. 1, 115 D.L.R. (3d) 257.

3. 19 C.C.L.T. 1 (SCC).

4 Supra n. 1 at 236.

5. Report of Committee on Tort Compensation (Holland Report) 1980.

6. Report on Personal Injury Litigation - Assessment of Damages (56) 1973. 
States appear to be inordinately high and, particularly in the field of medical malpractice, insurance premiums are prohibitive. Hopefully something can be done in Canada before the problem reaches the proportions that it has in the United States.

No doubt, in large measure, as a means of self-defence, insurers in the United States are leading the way in developing what have become known as Structured Settlements. Rumour has it, however, that some of the very first structured settlements were actually used in Canada in 1968 in claims arising from the Thalidomide cases. The phrase, however, appears to have been coined in the United States, perhaps in California, and at this stage has become a common method of concluding settlements. Several states have passed legislation in one form or another to facilitate various aspects of this form of settlement and at present, work is being done by a uniform law committee with a view to standardizing the legislation. $^{7}$

While the first structured settlement may have been in Canada in 1968, it has only recently returned to this country via the United States. The most familiar example of its use at present is found in the case of Yepremian v.Scarborough General Hospitalet $a h^{8}{ }^{8}$ where a basis for settlement by way of a structure was reached pending the hearing of the appeal by the Supreme Court of Canada. Structured settlements, however, have been in use in British Columbia for some time, largely due to the efforts of the Insurance Corporation of British Columbia, and indeed, many settlements have been concluded both in Ontario and in other provinces without the publicity that has been accorded to the Yepremian case.

Structured settlements have also been the subject of seminars sponsored by the Law Society of Upper Canada ${ }^{9}$ and the Legal Education Society of Alberta. ${ }^{10}$ No doubt similar programs have been or are being arranged in other provinces.

\section{WHAT IS A STRUCTURED SETTLEMENT?}

Any settlement agreement that provides for payments other than the conventional lump sum single payment could presumably be termed a structured settlement. The complexity could range from an agreement that part of the funds be paid now and the balance a year hence, to a situation whereby some monies are paid now, future monies are arranged to be paid monthly to the claimant for life, endowment plans are included for claimants' children, and term life insurance arranged to be payable upon certain events. Indeed, the possible complexity of a structured settlement is limited only by the ingenuity of the parties involved and the state of the art in the life underwriting industry.

A normal structured settlement, at least at this stage of its development, provides first of all for the payment of whatever funds are required to cover expenses already incurred by the claimant or to finance the purchase of items immediately needed by the claimant. Those funds are referred to commonly as 'upfront monies' and normally include special

7. A good discussion of the American situation is found in Daniel W. Hendert, "Periodic Payment of Personal Injury Damages" (1980) 31 F.I.C.Q. 3 and in W.E. Sedgewick and W.C. Judge, "The Use of Annuities in Settlement of Personal Injury Cases"(1974) 41 Ins. Coun. J. 584.

8. (1981) 15 C.C.L.T. 73 (Ont. H.C.).

9. Dept. of Cont. Legal Ed., L.S.U.C., Structured Damage Settlements (1981).

10. L.E.S.A., Selected A spects of Personal Injury and Fatal Accident Litigation (1981). 
damages incurred to the date of the settlement, the costs of home renovations or special equipment required by the claimant, and the claimant's solicitor-client fees. The purposes of the upfront monies is to look after the claimant's immediate financial needs.

The settlement then normally provides for a series of future payments with a view to looking after the claimant's future financial needs as they occur, the most common being the provision for monthly payments to the claimant for life. Where it can be anticipated that at some future point an unusual or additional expense will be incurred, provision can be made for that payment. Also, where it can be anticipated that the claimant's expenses will increase or decrease at a given point, adjustments to the payment schedule can be made accordingly. Those types of adjustments are particularly useful in concluding fatal accident claims with a view firstly to providing extra funds when required for the cliildren's education and then making allowance for the fact that the widow's expenses will decrease once the children are independent.

The types of future payments, including indexing, guarantee periods, and other possible variations, will be dealt with later.

The objective is to arrange a combination or series of payments that will best suit the particular needs of the claimant involved and ensure further that neither will he run out of funds during his lifetime nor will there be any unexpected windfall to undeserving relatives should he die prematurely.

\section{ADVANTAGES}

Structured settlements are in large measure made feasible as a result of income tax laws in both Canada and the United States. Lump sum settlements received by a claimant for personal injury are not income and therefore not taxable in his hands. However, any income earned on that sum is taxable and, especially in cases of larger awards, is a significant problem. Indeed, in some cases an additional sum referred to as a 'grossing up' has been given to a claimant to try to compensate for the effects of taxation. If that practice becomes common it will only serve to increase damage awards that much more. Even if the claimant invests the funds in the form of an annuity, he will be taxable annually on the income portion of that annuity. Certainly there are a variety of tax avoidance schemes of which an intelligent claimant can take advantage, but the fact remains that income taxation becomes a very real concern to the recipient of any large damage award. It appears that it matters not from a taxation point of view whether damage awards are received by the claimant in one lump sum or in a multitude of payments. Those payments continue to be received as damage payments and not as income. A recent Revenue Canada interpretation bulletin dealing with damages, settlements and similar receipts is very relevant. Sections 5, 6 and 13 of IT-365R, issued March 9, 1981, read as follows:

Receipts in Respect of Personal Injuries

5. A mounts in respect of personal injuries or death may be received on account of any or all of the following:

(a) Special damages - examples are compensation for

(i) out-of-pocket expenses such as medical and hospital expenses, and

(ii) accrued or future loss of earnings;

(b) General damages - examples are compensation for

(i) pain and suffering.

(ii) the loss of amenities of life,

(iii) the loss of earning capacity, and 
(iv) the shortened expectation of life;

(c) Amounts as compensation for loss of support may be paid to the dependents of the deceased. All amounts in (a), (b) and (c) above will be treated as non-taxable receipts provided that they can reasonably be considered as compensation in respect of personal injuries and not income from employment or a termination payment. (See IT-202R Workmen's Compensation Payments; Injury Leave Pay or Similar Payments). An amount of such a compensaton is non-taxable even though the quantum of the compensation is determined with reference to accrued loss of earnings to the date of award or settlement or to future loss of earnings.

6. The method of payment (periodic or lump sum) is not an important factor in determining the taxability of an award or settlement for personal injuries or death. However, where an amount that has been determined to be non-taxable is paid on a periodic basis, see 13 below for taxing of interest element, if any.

Interest Element in Awards for Personal Damages

13. Where payments for damages that have been awarded by a Court or resolved in an out-of-court settlement, in respect of personal injuries or death, are paid on a periodic basis, the payments will not be considered to be annuity payments for the purposes of paragraph $56(1)(d)$ and 60 (a). Accordingly, no part of such payments will be treated as interest income. However, where an award for damages has been used by the taxpayer or his representative to purchase an annuity, the amounts received will be considered as annuity payments under paragraphs 56(1)(d) and 60(a) and Regulation 300 . A bulletin on the subject of annuities is presently being prepared for publication and will comment on annuity payments in greater detail. Where awards for damages are held in deposit, the amount of interest earned will usually be determined and included in the taxpayer's income annually. Where an award for damages is held in trust, any interest earned on the funds that is retained by the trust is income of the trust or of the beneficiary depending on the circumstances.

It should be noted that a bulletin is being prepared by Revenue Canada on the subject of annuities. To date there is no reported decision interpreting relevant sections of the Income Tax Act in reference to structured settlements and it should be appreciated that IT-365R is an interpretation bulletin only. A review of the relevant sections of the Income Tax Act, however, leads to the conclusions expressed in IT-365R; namely, that a damage payment in whatever form continues to be a damage pay. ment and is accordingly not taxable as income in the claimant's hands.

Certainly, if an attempt were made to disguise some form of investment scheme as a schedule of damage payments, a court would quite likely deem those payments to be income and taxable accordingly. However, as long as the payments are bona fide damage payments to a claimant, they should not be treated as income in his hands.

The fact that the payments to the claimant may be funded by the defendant's insurer through the purchase of an annuity does not change the character of those payments. Indeed, the most common way of funding the periodic payment portion of a structured settlement is for the defendant's insurer to purchase a non-assignable and non-commutable annuity and, while remaining owner of the same, to instruct that the payments be made directly to the claimant. The annuity itself and the income therefrom continue to belong to the defendant's insurer and it is required to declare that income annually for tax purposes. Because, however, it is in the business of providing casualty insurance, the payments made to the claimant are treated as an expense against the income earned on the annuity. While the foregoing states the situation much too simply, the casualty insurer does, using approved reserving procedures, ultimately have a nil tax position.

The significance of tax free payments to a claimant can be readily appreciated, even if the claimant is in a lower tax bracket. A claimant in a 25 per cent tax bracket and requiring $\$ 1,500.00$ a month to meet his expenses would require a before tax income of $\$ 2,000.00$. He would require an annual income of $\$ 24,000.00$ to meet those expenses, but if instead he were to receive damage payments totalling $\$ 18,000.00$ annually, he would be put in exactly the same net position. A difference of $\$ 6,000.00$ per annum over 
his additional lifetime, of perhaps 40 years, is rather significant. As a claimant's tax bracket increases (and it certainly does at least initially with the larger lump sum awards) the benefits of a structured settlement become even more apparent.

A claimant can, through a structured settlement, be put in as good a net position after tax as he would be with a lump sum settlement at considerably less cost to the defendant's insurer, which is one of the reasons the insurance industry as a whole both in Canada and the United States has taken a very active role in the development and use of the structured settlement. That does not mean that the whole benefit of the structured settlement does or indeed should go to the defendant's insurer. What it does mean is that the defendant's insurer can put the claimant in a better position with a structured settlement than it could have done with a lump sum settlement, and at less cost to that insurer, so that both parties benefit in the end result and in some cases significantly so. There will be cases where the claimant's tax bracket is so low or the damages so small that the tax free damage payments will be of little benefit to him. There will also be cases where a claimant has available to him methods of avoiding or reducing his taxes so that, again, the structured settlement would be of no real benefit to him. Those claimants no doubt would instead choose a conventional lump sum settlement.

Another obvious advantage of a structured settlement is that it removes the danger of the claimant, who in most cases is totally unaccustomed to handling large sums of money, mishandling the funds through poor investments or frivolous purchases. The proper investment of large sums to ensure an adequate return of income, whatever the economic conditions, is no easy task. In fact, it is becoming more common to find claimants receiving lump sum payments being given an allowance for professional money management fees, sometimes in significant amounts.

There is no doubt that once the terms of a structured settlement have been implemented they cannot be altered. It is precisely that aspect of the structured settlement that protects the claimant from well-meaning (or otherwise) friends and relatives and, indeed, from himself. It ensures that the proceeds of the settlement will protect his financial future as far as the available funds will allow and without the necessity of any money management advisors.

One of the major criticisms of the conventional lump sum payment method is that it can produce serious shortfalls. A very real danger of shortfall, even with the wise investment of funds, arises if the claimant lives longer than the normal life expectancy. If a 20 per cent contingency allowance is also applied, and solicitor-client and other fees are all deducted from the lump sum before it is given to the claimant for investment, he would be doing well indeed to make those funds last for even his normal life expectancy.

Of course, the claimant can take what he has left of the lump sum and invest it in an annuity that will guarantee him payments for life, but he will be taxed on the income portion of that annuity and the amount he can invest in that annuity will be what is left of the lump sum. By contrast, the structured settlement can give him monthly payments for life that are tax free and in an amount that has been worked out in the overall planning of a package that will suit his particular needs. 
Perhaps the greatest advantage that a structured settlement has over the conventional lump sum method of assessment of damages is that the planning of the structure involves a real and practical consideration of the claimant's needs, rather than a strictly legal and sometimes very artificial appraisal of what the claimant is 'entitled' to in a courtroom. The claimant is more interested in seeing that his bills are paid than he is in knowing that his general damages should be $\$ 100,000.00$ or that his discount rate should be 3 per cent.

This is not to say that we do not need guidelines in the assessment of personal injuries or that the amount of funds put into a structured settlement package for the claimant should not bear some relationship to the value of his claim according to conventional standards. Also, it is clear that the liability picture needs to be taken into account when assessing the potential value of the claim. It is to say, however, that it is a fundamental principle of our assessment procedure that two claimants with similar injuries should not as of right receive identical awards but rather that each of them should be compensated according to the damage he has suffered. That is not accomplished by compensating him for damages he might have suffered or that someone else may have suffered. There appear to be very strong arguments that the structured settlement better accomplishes this task than do our conventional methods of compensation.

There is also a very real danger under the conventional payment system of creating a windfall situation where a claimant dies prematurely. This is initially at the expense of the casualty insurer involved but ultimately at the expense of all of us in the form of higher insurance premiums. Under a structured settlement, due consideration can be given to whether in the event of premature death, any dependents have a need of the continuing payments. If they do, a guarantee can be included in the structure. If not, the payments can revert to the defendant's insurer and there would be a substantial saving to the insurance industry as a whole if unneeded payments no longer had to be made.

\section{DISADVANTAGES}

One of the main advantages of the structured settlement could also considered to be its major disadvantage; namely, that upon its implementation it cannot be altered, revoked or otherwise interfered with. It is as full and final a settlement as any other and it not subject to review. It commits the claimant to a series of payments that will not fluctuate in response to changes in economic conditions. It would leave the claimant powerless in the face of runaway inflation and provide a bonanza in the event of a severe depression. It has, in that sense, many of the attributes of a life annuity and there are many who do not view the purchase of an annuity as a wise investment.

There is also the criticism that the claimant's damage award is his to do with as he pleases and that a structured settlement virtually takes away that right.

There is also the very valid point that there will be many cases where a structured settlement is not appropriate to a claimant's needs, whether it be because he has available to him a form of investment that will out perform both the annuity and the tax benefits offered by the structured settlement, or where for his own reasons he wishes to manage his own finances. In those cases a structured settlement should not be used. 
Certainly the advantages of a structured settlement decrease as the amount of the claimant's damages decrease. The lower the amount, the less danger of the claimant mismanaging it and the less likelihood of any real tax benefits. A point is reached where the costs of working out and implementing a structured settlement would outweigh any benefit to be gained by it.

\section{PROCEDURE}

The handling of a structured settlement case is not unique in the early stages. The claimant's lawyer is concerned with accumulating medical and other information, keeping track of expenses and doing all those things normally related to a personal injury or fatal accident claim. At the same time, the defendant's insurer is equally concerned with receiving relevant information as it becomes available so that adequate reserves can be posted.

With the conventional approach, when sufficient material is available, both parties attempt to assess the value of the claim and then possibly try to negotiate a compromise figure. If that fails, the matter then proceeds to litigation.

The approach in a potential structured settlement situation usually differs in that there would be more co-operation between the parties and at an earlier stage because both parties stand to benefit from the successful conclusion of negotiations, with the focus throughout being on the actual needs of the claimant.

Of course, the claimant's lawyer will be advising the claimant of the value of the claim using conventional methods, and the defendant's insurers and their lawyer will be mindful of the minimum and maximum figures likely to be awarded by a court. Indeed the claimant can and should compare any proposed structure to the probable conventional lump sum settlement or court awards and should be satisfied that the structure is in fact providing more benefits to him.

At a very early stage in any negotiations leading towards a structured settlement, the help of an annuity expert will be required. In order to start making a vailable useful figures for discussion purposes, the expert will need the date of birth of the claimant, together with sufficient medical information to indicate whether the claimant has a normal life expectancy, or if it is a reduced one, by how much. Certainly, there is an instance where it is as much to the claimant's benefit as to the defendant's to establish a reduced life expectancy, if there is one, as the annuity to be purchased to provide the monthly payments will be more per month the lower the life expectancy. If negotiations toward a structured settlement broke down and the matter reverted to litigation using conventional methods, the claimant would no doubt want to reverse his position and argue that his life expectancy was a normal one.

The actuarial expert will also require information concerning the need for guarantee periods. As indicated earlier, the monthly payments under the structured settlement normally continue for the life of the claimant whether he lives longer than the normal life expectancy or he dies prematurely. If there is a spouse or other dependents, it may not be satisfactory to the claimant to have those payments stop in the event of his premature death. A guarantee period can be specified so that the payments will continue to be made to a dependent for whatever the required period. If the claimant has no dependents, there is no need for the 
guarantee period and in the event of his premature death, arrangements should be made to have the payments revert to the defendant's insurers, as earlier discussed.

Once sufficient particulars are provided to the actuarial expert, he will be able to provide at least some approximate figures for discussion purposes. He can work out several alternate proposals in order to acquaint the claimant with the range of possibilities that exist, while at the same time advising the defendant's insurer of the actual cost of the various proposals.

There has been considerable discussion (and difference of opinion) particularly in the United States, as to whether a claimant can or should be told the actual cost to the defendant's insurer of the package. One school of thought is that he is entitled to know as a right what that cost is, whereas others hold the view that he should not be told under any circumstances. The logical answer would seem to be that the claimant's concern is to compare what is being offered by way of a structure to what he might obtain in court by way of conventional means of compensation and it is really not relevant to the determination of that question to know what the structured settlement package is costing the defendant's insurer. There does not seem to be any particularly compelling reason why an insurer would not want to divulge that information to a claimant other than it really is of no relevance to the claimant.

The annuity expert can also provide figures showing the effects of indexing on the monthly payments. Normally, if indexing is provided it is at 3 per cent or 4 per cent which is considered to be sufficient to protect against inflation on a long term basis, particularly when considering that the claimant receives the full amount of the annual increase and not just a net amount after tax. The higher the indexing, the lower the initial monthly payments will be, so that while higher indexing figures can be used, it is questionable whether a claimant would want to opt for what is considered to be an unnecessarily high indexing figure at the expense of reduced monthly payments in the initial years.

The need for additional payments at a future time should be considered and indicated to the annuity expert so that they can be included in the payment structure. This is particularly so in the case of infants where it may be anticipated that they will require additional funds at age 18 for educational purposes or additional funds at age 25 for the purchase of a house or a business investment. It is not uncommon to include in a structure an additional payment of perhaps $\$ 5,000.00$ over and above the monthly payments to be paid every five years as long as the claimant is alive. Those types of payments provide extra funds to the claimant to spend as he sees fit, or if necessary, to take care of unexpected expenses.

Almost any variation that the parties feel is needed and that can be accomplished by the life annuity industry can be included in the structure. Such things as endowments, term life policies and any number and combination of annuities can be used to fund the package. In the normal case, however, a structure that adequately deals with upfront monies and provides monthly payments for life, with or without guarantee periods, indexing, and allowance for additional payments if any, is adequate.

In the early stages of discussions, the figures being provided by the annuity expert are approximations and are used largely for illustration purposes to acquaint the claimant with the range of choices that he has. It should be pointed out that the defendant's insurers' primary concern is 
with the actual cost of the total package and it will be left entirely up to the claimant to select those features which he prefers to have in the plan. As the claimant becomes familiar with the options available to him and is able to start selecting the features he prefers, negotiations can begin in earnest.

A problem which remains until the very final stage is that the actual benefit to be provided at a given cost cannot be determined until the defendant's insurer actually commits itself to the purchase of a specific package. The casualty insurers normally fund structured packages by the purchase of annuities from life underwriters. Those underwriters in turn fund the annuities on the open money markets which fluctuate from day to day, and thus the price of the annuities fluctuate. The life annuity industry is presently trying to work out arrangements with the casualty insurers whereby a price of a package can be quoted and held open at least for sufficient time to enable the casualty insurer to be informed of the price, communicate a proposal to the claimant, receive the claimant's acceptance and then purchase the package at the offered price. As matters now stand, the casualty insurers would have to take the risks of a rising or falling money market in making a specific proposal for settlement to a claimant and then have to purchase that package several months hence. It will accordingly be apparent that a specific proposal for settlement will not and cannot be made to a claimant in a form that allows him an indefinite period of time to consider the same.

In practice, the problem is dealt with by making it clear that the figures being discussed are approximations and that only in the final result will specific figures and payment schedules be provided.

Once provided, acceptance or rejection must occur with due dispatch, failing which new figures will have to be obtained. Certainly, negotiations toward final figures can carry on for as long as the parties find it necessary, but in the final stage, the plan must be implemented quickly if it is to be implemented at all.

The importance of the claimant (and his lawyer) fully understanding what he is receiving by way of the structure must be stressed. One of the major criticisms of structured settlements is that they can be interpreted by the uninitiated as giving the claimant substantially more than is actually the case. Newspaper reports abound in the United States to the effect that a particular claimant has been awarded perhaps 2.2 million dollars when in fact what the claimant has received is a structured settlement that, if he lives a normal life expectancy, will result in payments in that total amount being paid to him. The present value of the award is not 2.2 million dollars and the claimant should clearly understand that if he were instead to receive a lump sum settlement and properly invest the same, the total return to him over his lifetime would also be a rather large amount. Using proper comparisons, the structured settlement should provide significantly more benefits to the claimant but the claimant clearly needs proper advice which will allow him to compare the true benefits of the structure in comparison to the lump sum settlement. It is the duty of the claimant's lawyer to ensure that the claimant does have the proper information and is fully informed as to his options before making his final decisions. The casualty insurance industry as a whole has no desire to have the true benefits of a structured settlement misrepresented to the claimant and should not be faulted if the claimant's legal advisors do not properly present a true picture to him. 
During the course of negotiations, the claimant will no doubt prefer to have as much upfront money as possible. Of course all of his expenses should be paid, including solicitor-client fees, and enough funds should be provided to purchase any items required immediately for his care or convenience. He would then like to have as much money left in his bank account as possible for whatever purposes he may choose, but it should be realized that the more money that is paid upfront, the less there will be a vailable to fund the future payments. Increased future payments will, in the end result, be of much greater value to the claimant than would be an additional $\$ 10,000.00$ in the bank now, and he should be given comparative figures so that he can make an intelligent decision as to how to divide the funds. The provision in the structure of additional payments, as previously discussed, of perhaps $\$ 5,000.00$ every five years often alleviates a claimant's fears that the structure will leave him a budget for life with no room for spontaneous purchases.

The claimant will also want the highest monthly payments with the highest indexing rate he can negotiate. The defendant's insurers will be willing to accommodate his choice of options but will resist any counterproposals that increase the overall cost of the package. In this sense, negotiations will be much the same as they are in any situation where the parties are financially adverse in interests, the only difference here being that both parties will realize that their respective situations will be worsened, not improved, by proceeding to litigation in the normal manner. With this added inducement to settle, a compromise is usually more readily reached than in the case of ordinary litigation.

\section{ILLUSTRATIONS}

It is helpful to look at a few typical examples of where a structured settlement may be of benefit. Let us assume a case of John Smith, born July 1,1948 , who was rendered a paraplegic at age 32 at a point when he was earning $\$ 36,000.00$ a year. Using conventional assessment methods, and simplifying the same as much as possible, his lost earning capacity to age 65 discounted as $2^{1 / 2}$ per cent would have a present value of $\$ 770,235.00$. His general damages would be approximately $\$ 100,000.00$ and he would have additional expenses as well. A structured settlement could be arranged for John Smith replacing his annual income of $\$ 36,000.00$ a year, indexed at 3 per cent, with an additional upfront payment to him of $\$ 100,000.00$, at a cost to the defendant's insurer of approximately $\$ 422,800.00$. If the annual payments were indexed instead at 4 per cent, the cost of the entire package would increase to $\$ 456,700.00$. $^{\prime \prime}$

Situations may arise where the claimant will have a greater need for funds at some later date then he does at present. We can assume the case of Bill Brown, who at age 25 suffered serious physical injury estimated to be 25 per cent of total, thus preventing him from engaging in physical labour. Bill Brown, however, overcame his physical disabilities and returned to work in the sales field six months after the accident. His actual loss of income was $\$ 15,000.00$ and his other special damages $\$ 15,000.00$, so that an assessment of his claim using conventional methods would be in the $\$ 60,000.00$ to $\$ 70,000.00$ range. A structure can be devised

11. As indicated earlier, the help of an actuarial expert is necessary in order to provide figures even for discussion purposes. The writer is indeed indebted to George Edgelow of Edgelow Insurance Agencies in Edmonton and Robert G. Baxter of Baxter Structured Annuities in Toronto for their time and assistance in providing some realistic figures for the writer's imaginary cases. 
for $\mathrm{Mr}$. Brown consisting of a cash payment of $\$ 27,500.00$ followed by monthly payments of $\$ 200.00$ a month to age 55 . At age 55 , anticipating his retirement at that point, the monthly payments would increase to $\$ 1,153.00$, with a guarantee period of 20 years for the benefit of his wife. The cost of the package to the defendant's insurer would be $\$ 62,500.00$.

Situations involving infants are usually ideal for structured settlements. Let us assume the case of five year old Linda Jones who received moderate injuries, including facial scarring, having a value by conventional standards of $\$ 16,000.00$ to $\$ 17,000.00$, including special damages. She is expected to require plastic surgery at age 16 . Normally, in Alberta, those funds would be paid to the Public Trustee and invested on her behalf. At age 18, the entire fund would be turned over to her to use in whatever fashion she saw fit. In the case of an infant, the income earned on the settlement monies, as well as the funds themselves, are not subject to tax and the tax free status of the income earned on the settlement monies continues to age 21 .

Using a structured approach instead, the sum of $\$ 1,000.00$ would first of all be provided for the operation at age 16 . Commencing at age 18 , she would receive monthly payments of $\$ 500.00$ to continue three years. At age 21 she would receive a lump sum of $\$ 25,000.00$ and at age 25 a final lump sum of $\$ 100,000.00$. The cost of the package to the defendant's insurer would be $\$ 12,500.00$.

Concern has been expressed as to whether structured settlements are appropriate at all in the case of infants. The first difficulty is that it would have to be the parents or guardians and the Public Trustee jointly who make the decision as to whether to structure the settlement, and if so, in what manner, subject to the final approval of the court. Caution has to be exercised on the part of these individuals in binding the infant to the provisions of a settlement that carries on past the age of majority. It is generally considered that while it may be wise to have the structured provisions carry on past the age of 18 , they should not bind the infant for life, and unless there are some unusual circumstances, the entire benefit of the structure should have been put in the infant's hands by the time he is age 25. The justification for having the terms of the structure carry on past age 18 would be that a 25 year old is in a much better position than is an 18 year old to make appropriate decisions as to how to invest large sums of money. Certainly, if the infant has an injury of a nature that will render him a dependent adult upon reaching the age of majority, those particular considerations do not apply. Again, it is cautioned that the parents or guardians with the assistance of the Public Trustee will have to make a proper comparison of the benefits possible under a proposed structure to the benefits that would otherwise accrue to the infant in any event if the monies were simply turned over to the Public Trustee's Office for investment on his behalf.

Even in a case where there are wholly inadequate policy limits available, a structured settlement may be in the claimant's best interest. A good illustration would be a situation where a 19 year old girl suffered severe brain injury and physical impairment and is wholly incapable of managing her affairs. The family can neither physically nor financially care for her. She will be confined to an institution for life with no one other than the Public Trustee available to manage her affairs. The defendant's insurer would have the options of offering the policy limits of $\$ 200,000.00$ to the Public Trustee or instead, of proposing a structured settlement. At 
a cost to the insurer of $\$ 170,000.00$ a structure could be offered producing income of $\$ 1,468.00$ per month indexed at 3 per cent and guaranteed for 20 years. It may in fact be established by medical evidence that the girl had a substantially reduced life expectancy as a result of her injury. If for example a reduction of 21 years could be medically demonstrated, the defendant's insurer, at the same cost, could offer payments of $\$ 1,628.00$ per month.

It may be possible for similar proposals for structured settlements to be made by Unsatisfied Judgment Fund authorities when they, rather than insurers, are involved.

\section{CONCLUSION AND IMPLEMENTATION OF A STRUCTURED SETTLEMENT}

There appears to be no need to have a structured settlement concluded by way of a Judgment unless the situation is one requiring court approval, as in cases involving infants or mentally incapacitated adults. If infants or mentally incapacitated adults are involved, or if there is any other reason to obtain a Judgment, the matter should be concluded in that fashion as was done in the Yepremian case. ${ }^{12}$

In the normal structured settlement case, release documents will be adequate but it should be realized that the form of release is significantly different than in the normal case. The first difficulty is that it is not intended that the defendant will be personally responsible for the continuing future payments. The second difficulty is that the defendant's insurer must retain ownership of any annuities used to fund future payments. It is the insurer who is making the guarantee and undertaking to the claimant that the payments will be made and must accordingly continue to remain liable to the claimant throughout the life of the structured settlement.

The problem has been solved by drafting release documents to provide that in consideration of the claimant receiving the 'upfront' monies and costs, and the undertaking of the defendant's insurer to make future periodic payments, the claimant first of all provides a complete release to the defendant personally and further releases the defendant's insurer from any possible further liability to the claimant under any policies issued to the defendant relating to the accident which caused the damage. In other words, the claimant completely releases both the defendant and his insurer from all liability resulting from the accident and receives in substitution the commitment of the defendant's insurer to make the future payments as well as actual payment at the time of settlement of the upfront monies and costs.

As indicated earlier, it is crucial from an income tax point of view that if an annuity is purchased to fund the future payments, the defendant's insurer remain the owner of the same and the annuity specifically be both non-assignable and non-commutable and the documentation should record the situation accordingly. Indeed, where such purchases are to be made, the settlement documents can so specify. It is also normal to attach to the release documents an actual schedule of the payments to be made and to refer to that schedule as an appendix to the agreement itself. There should then be no difficulties between the parties as to what payments are due and in what amounts. The actual terms of the settlement will vary from case to case but in each case, the particulars of the settlement should be recited in the release documents.

12. Supra n. 8. 
Concern has been expressed as to the degree of security a claimant is actually receiving to ensure that the payments are made in the future. What he has in fact is the undertaking of a casualty insurer that the payments will be made and the knowledge that the casualty insurer has, either by way of purchase of annuities or by internal funding, provided the means whereby those payments will be made. If instead actual funds were set aside for the claimant by way of trust, guarantee or other device, those funds could then be deemed to have been received by the claimant for tax purposes and the income from the same taxable in his hands. In order for the payments to retain their tax free status as damage payments, control over those funds cannot be transferred from the defendant's insurer to the claimant.

It is an economic fact that a casualty insurance company could go bankrupt, as could the life company providing the annuity. It is also an economic fact, however, that any trust companies, banks or other institutions in which a claimant might invest his funds, could also go bankrupt. This can then lead to lengthy philosophical discussions as to whether our insurance industry is any more or less stable than our banks and trust companies. Our insurance industry is closely regulated and stringent reserving procedures have long been in force. The Offices of the Superintendent of Insurance for Alberta or for Canada can answer any questions the claimant may have as to the stability of a particular insurer.

\section{FINAL REMARKS}

It appears that the structured settlement is here to stay. The tax benefits are obvious as is the protection it offers to the claimant against the funds being mismanaged. It can also be used to protect against either shortfalls or windfalls.

The structured settlement, however, is not the answer to all our problems. It does nothing to satisfy the apparent need for periodic reviews of assessments, nor can it or should it be a compulsory mode of settlement at this stage in its development.

One can hope that the life annuity industry will one day be able to offer a form of monthly payment for life which will effectively cope with periods of inflation as well as depression so that a claimant will indeed be given the real purchasing power he requires over his lifetime to meet his needs. It is wishful thinking to hope that we will some day arrive at a system of perfect compensation. Structured settlements, however, are a step in the right direction. 